\title{
$\mathrm{V}-\mathrm{ROI}$ 를 이용한 고효율 실시간 차선 인식 알고리즘
}

\section{Efficient Real-time Lane Detection Algorithm Using V-ROI}

\author{
Ding Dajun* , 이찬호*^ \\ Ding Dajun*, Chanho Lee ${ }^{* \star}$
}

\begin{abstract}
Information technology improves convenience, safety, and performance of automobiles. Recently, a lot of algorithms are studied to provide safety and environment information for driving, and lane detection algorithm is one of them. In this paper, we propose a lane detection algorithm that reduces the amount of calculation by reducing region of interest (ROI) after preprocessing. The proposed algorithm reduces the area of ROI a lot by determining the candidate regions near lane boundaries as V-ROI so that the amount of calculation is reduced. In addition, the amount of calculation can be maintained almost the same regardless of the resolutions of the input images by compressing the images since the lane detection algorithm does not require high resolution. The proposed algorithm is implemented using $\mathrm{C}^{++}$and OpenCV library and is verified to work at $30 \mathrm{fps}$ for realtime operation.
\end{abstract}

\section{요 약}

자동차가 IT 기술과 융합되면서 편의성과 안전성 그리고 성능이 좋아지고 있다. 이와 관련하여 최근 자동차의 주 행시 안전 및 주변 환경과 관련된 정보를 제공하기 위한 많은 알고리즘이 연구되고 있으며 차선 인식 또한 그 중 하나이다. 본 논문에서는 입력된 영상에서 차선 경계선을 인식한 뒤 ROI를 경계선 주변으로 제한하여 연산량을 줄이는 알고리즘을 제안한다. 제안된 알고리즘에서는 선처리 과정을 통해 차선 경계선으로 추정되는 영역의 주변 만을 $\mathrm{ROI}$ 로 지정하는 $\mathrm{V}-\mathrm{ROI}$ 를 이용하여 연산 영역을 줄이고 이를 통해 연산량과 연산 시간을 줄인다. 또한 차선 인식의 경우 고해상도의 영상이 필요하지 않으므로 입력 영상을 축소하여 차선 인식 알고리즘을 적용하는 방법을 통하여 영상의 해상도에 관계없이 연산량을 비슷하게 유지할 수 있다. 제안한 알고리즘을 $\mathrm{C}++$ 와 $\mathrm{OpenCV}$ 라이브 러리를 이용하여 구현하였으며 초당 30 프레임 이상을 처리하는 실시간 동작을 확인하였다.

Key words : pattern recognition, ROI, smart car, OpenCV, lane detection

* ding.dajun@gmail.com, 02-825-8108, Dept. of Electronic Engineering, Soongsil University

* chlee@soongsil.ac.kr, 02-820-0710, School of Electronic Engineering, Soongsil University

* This work was sponsored by Industrial Strategic Technology Development Program funded by the Ministry of Knowledge Economy (MKE, Korea) (10039188, Development of multimedia convergence programmable platform for smart vehicles). The EDA tools are supported by IDEC.

Manuscript received Oct. 3, 2012; revised Nov. 14, 2012 ; accepted Nov 19. 2012

\section{I. 서론}

자동차에 IT 기술이 접목되어 지능형 자동차 개발 이 활성화되고 있고 이에 따라 자동차의 편의성과 안 전성 그리고 성능이 크게 개선되고 있고 이를 위한 연구 또한 활발히 진행되고 있다. 이러한 연구는 자 동차 주행과 관련하여 성능 및 안전성을 개선하는 연 구와 차량의 상태 및 주변 환경 등의 정보를 제공하 여 편의성과 안전성을 높이는 분야로 나누어지는데 후자의 경우 카메라를 통한 영상을 분석하여 주변 상 
황을 인식하는 연구가 중요한 부분을 차지한다.

그중 하나인 차선 인식은 차선에서 차량의 위치 와 방향을 추정하는데 이용 가능하다. 이를 이용하여 자동차 전용도로 등에서 차량의 차선 이탈을 감지하 여 운전자에게 알려주고 모든 주행 상황에서 차선을 인식하여 자동 운전 시스템에서 차량이 차선을 이탈 하지 않고 주행하기 위한 정보를 제공한다[1-9]. 또한 다른 차량의 위치와 장애물에 대한 정보를 제공하여 장애물 회피 시스템에서도 이용될 수 있다. 차선 인 식을 위해 카메라, 선 인식 센서, 레이저 탐지, GPS 등의 다양한 센서를 이용한 방법이 연구되었는데 이 중에서 카메라를 이용한 방식이 가장 광범위하게 특 정 조건에 구애받지 않고 사용 가능하다[2]. 카메라를 이용한 영상 인식 방식은 선 인식이나 레이저 탐지 방식처럼 차량 외부 또는 도로에 별도의 장치를 필요 로 하지 않고 GPS 신호를 이용하는 방식이 요구하는 축적된 지도 정보 등이 없어도 정확한 위치 정보를 제공할 수 있다.

영상 인식을 기반으로 한 차선 인식 알고리즘에서 입력된 영상으로부터 차선 경계선 추출은 가장 핵심 적인 동작으로 차량이 차선 안에서 좌우로 조금씩 움 직이고 차선도 항상 직선을 유지하지는 않아 하나의 특징 추출로는 인식이 어렵다. 따라서 적절한 임계치 설정, 가장자리 탐지와 선 탐지 등의 방법을 통해 실 시간으로 이루어진다. 패턴의 가장자리를 인식하는 방법은 차선 경계선처럼 두꺼운 분할선 인식에 적합 하고 야간 주행을 돕기 위한 반사판에 의한 영향을 보상하는 데도 이용 가능하다[2]. 차선 인식을 위해 $\mathrm{Xu}$ Zhe[3] 등은 Canny 방식과 Progressive Probabilistic Hough Transform(PPHT)을 사용했고 S. Zhou[4] 등은 기하학적 모델과 Gabor 필터를 이 용한 방식을 사용하였다. C. Jung[5] 등은 가장자리 탐지와 최소 제곱 각 예측 (least squares angular estimation), 그리고 Hough 변환(Hough Transform) 을 사용하여 차선을 인식하였다. 실험 결과에 따르면 대체로 차선을 잘 인식하나 도로의 그늘진 곳이나 간 섭이 있는 경우에는 문제가 있다.

고속도로의 중간 차선은 매우 환경이 좋은 편이지 만 가장자리 차선이나 도심의 시가지 등 도로 환경이 매우 복잡한 경우에는 관심 영역(Region of Interest, $\mathrm{ROI}$ )의 선택이 차선 인식에 중요한 요소로 작용한다. $\mathrm{ROI}$ 의 선택은 인식율과 인식 성능 모두에 중요한 영 향을 미친다. $\mathrm{Xe} \mathrm{Zhu}$ 등은 $\mathrm{ROI}$ 를 설치된 카메라의 높이와 피치 각에 따라 설정하였는데 가로로 가운데 의 $1 / 3$ 또는 $1 / 2$ 의 영역을 선택하였다[3]. 선택된 영 역은 직사각형 모양으로 프레임 간에 변경이 안 되어 고정된 영역을 가리키게 된다. V. Gaikwad 등은 카
메라 입력 영상의 아래 부분을 ROI로 선택하였는데 이를 다시 오른쪽과 왼쪽 영역으로 나누었다[6]. S. Zhou 등은 카메라와 도로 좌표의 관계에 따라 영상 을 분할하였다[4]. 차량 앞의 도로는 $10 \mathrm{~m}$ 를 기준으로 가까운 영역과 먼 영역으로 나누어 가까운 영역에 대 해서만 차선 인식 알고리즘을 적용하였다. 이 경우도 $\mathrm{ROI}$ 는 고정된 영역으로 선택된다.

기존의 차선 인식 알고리즘의 문제점 중 하나는 차 선 인식률에만 집중하여 인식 시간에는 큰 관심을 보 이지 않았다는 것이다. 따라서 인식 시간에 대한 언 급이 없거나 실시간성을 보장하지 못하는 경우가 대 부분이다.

본 논문에서는 ROI 영역을 줄여 연산량을 줄이는 차선 인식 알고리즘을 제안한다. 제안한 알고리즘에 서는 입력된 영상에 대해 선처리(preprocessing) 과정 을 통해 영상을 압축하여 이미지 크기를 줄이고 차선 경계선 후보를 선택하여 경계선의 기울기에서 일정한 값만큼 크고 작은 기울기를 갖는 두 개의 직선을 이 용하여 그 내부만을 적응적으로 $\mathrm{V}-\mathrm{ROI}$ 로 지정하는 방법을 통해 기존에 비해 연산량을 줄이면서 입력 영 상의 해상도에 관계없이 거의 일정한 연산량을 유지 하여 고해상도 영상에서도 성능이 저하되지 않는다. 제안한 알고리즘을 이용하면 하드웨어 가속기의 도움 이 없이도 실시간 차선 인식이 가능하다. 제안한 알 고리즘을 적용하고 $\mathrm{OpenCV}$ 라이브러리를 이용하여 윈도우즈 환경에서 차선 인식 소프트웨어를 구현하였 으며 노트북에서 실시간 동작함을 확인하였다.

\section{II. 직사각형 ROI 방식의 차선인식}

제안하는 $\mathrm{V}-\mathrm{ROI}$ 영역을 설정하기 위해서는 차선 경계선의 기울기를 알아야 하는데 첫 번째 프레임을 처리할 때는 이 기울기를 알 수 없으므로 직사각형 (Rectangular) ROI 방식을 통해 기울기를 구하는 $\mathrm{V}-\mathrm{ROI}$ 초기화 작업이 필요하다. II 절에서는 직사각 형 ROI를 이용하여 차선 경계선을 인식하는 방법을 설명한다. ROI 영역을 제외하고는 $\mathrm{V}-\mathrm{ROI}$ 를 이용한 방식에서도 동일한 알고리즘이 이용된다. 직사각형 $\mathrm{ROI}$ 방식은 $\mathrm{V}-\mathrm{ROI}$ 영역에서 차선이 사라져 초기화 할 때도 필요하다.

차선 인식 알고리즘에는 다음과 같은 가정이 포함 되어 있다.

1) 도로와 차선 텍스쳐는 일정하다 (consistent).

2) 도로와 차선의 폭은 국지적으로 일정하다.

3) 도로는 편평하거나 높낮이 차이가 있을 경우에 는 정해진 모델을 따른다. 
직사각형 $\mathrm{ROI}$ 를 적용한 방식은 기존에 발표된 방식 을 조합하였다. 즉, 카메라의 위치에 따라 전체 영상 의 $1 / 2$ 에 해당하는 고정적인 부분을 $\mathrm{ROI}$ 로 설정하고 선처리 과정을 거친 뒤, ROI를 좌우로 나누어 좌우의 차선 경계선에 대해 차선인식을 실행한다. 그림 1(a) 에 나타난 영상에서는 앞차와 내차 사이의 도로상의 차선을 인식하기 위해 그림 $1(\mathrm{~b})$ 와 같이 세로축에서 위에서 $1 / 3$ 지점부터 아래 $1 / 2$ 의 영역을 $\mathrm{ROI}$ 로 설정 하였다.

$\mathrm{ROI}$ 가 설정되면 해당 영역에 대해 그림 1 (c)와 같 이 무채색(grayscale)으로 변환한다. 이는 일반적으로 차선 경계선을 찾을 경우 배경보다 밝은 색을 인식하 여 처리하므로 색채는 필요 없기 때문이다. 무채색 영상은 다시 이진화 영상으로 변환하는데 이 때 임계 값에 따라 결과가 큰 차이를 보인다. 임계값은 날씨 와 도로상태, 시간대 등에 따라 달라지는데 상수값을 쓰게 되면 좋을 결과를 얻기 어렵다. 본 알고리즘에 서는 픽셀값의 평균과 분산을 이용하는 방식과 Otsu 임계값[10] 결정 방식을 개선한 방식을 상황에 따라 적용하도록 하였다. Otsu 임계값 결정 방식과 이를 개선한 방식이 평균과 분산을 이용하는 방식에 비해 상대적으로 연산량이 많기는 하지만 임계값 결정 단 계가 다른 연산 단계에 비해 단순하므로 전체 연산 시간에는 큰 영향을 미치지 않는다. 제안한 방식을 이용하면 임계값이 영상에 따라 적절한 값으로 변하 므로 영상의 상태에 따른 영향을 최소화할 수 있다. 또한 이 단계에서 그늘이나 가드레일 등에 의한 영향 도 최소화할 수 있다.

그러나 영상의 상태와 환경에 따라 이러한 영향을 완벽히 제거하지 못하는 경우가 발생한다. 그림 $1(\mathrm{~d})$ 에서는 점 잡음과 가드레일에 의한 대시선이 나타난 것을 볼 수 있다. 양쪽으로 흰 차선 경계선이 있는 경우는 임계값 조절로 대시선 제거가 가능하지만 노 란선이 있는 경우에는 무채색 변환 후 노란색의 밝기 가 흰색보다 약하므로 이를 보존하기 위해서는 임계 값을 낮추어야 하고 이에 따라 비슷한 밝기를 갖는 가드레일의 대시선이 사라지지 않는다. 이외에도 밝 은 작은 물체들이 있을 수 있으므로 이를 제거하는 단계가 필요하다. 일반적으로 차선 경계선의 수직성 분은 이러한 잡음보다 크므로 적절한 크기의 오프닝 (opening) 처리를 통해 제거하였다. 그림 1(e)의 예에 서는 $2 \times 5$ 크기의 직사각형 구성요소를 적용한 오프닝 처리를 통해 잡음을 제거하였다.

마지막으로 남은 차선 경계선에 대해 Canny 가장 자리 탐지 방법을 이용하여 가장자리 선을 탐지한다. 그림 1(f)에 나타난 바와 같이 매우 우수한 가장자리 탐지 방법 중 하나로 알려진 Canny 가장자리 탐지방
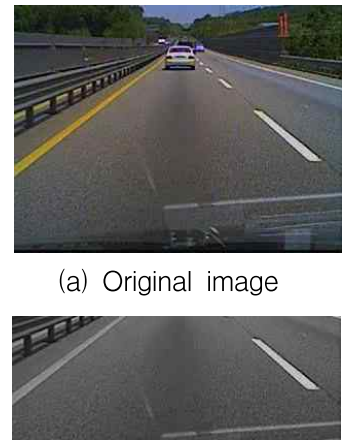

(c) Grayscale image

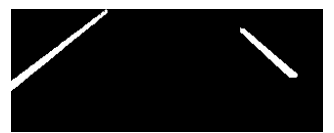

(e) Opening result (a) Original image

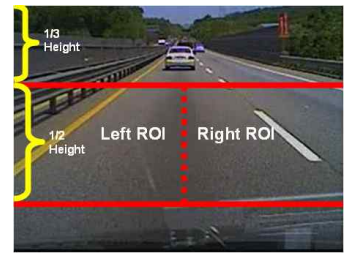

(b) Rectangular ROI

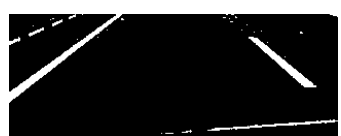

(d) Threshold result

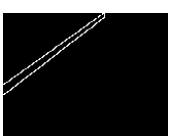

(f) Edge detection
Fig. 1. Lane detection procedure in rectangular ROI 그림 1 . 직사각형 $\mathrm{ROI}$ 방식의 차선인식 과정

법을 이용하면 한 픽셀 두께를 갖는 가장자리 선을 생성할 수 있다[7]. 최종 영상은 좌우 두 경계선에 대 해 새로운 두 개의 $\mathrm{ROI}$ 를 설정한다. 왼쪽의 $\mathrm{ROI}$ 와 오른쪽의 $\mathrm{ROI}$ 에 대해 적절한 각도를 갖는 선을 찾아 차선 경계선으로 설정한다. 그리고 그 외의 선들은 모두 제거한다.

차선의 위치는 Hough 변환을 이용하여 차선 경계 선을 직선에 맞추어 결정한다[1-6]. 차선 경계선의 직 선의 식은 다음과 같이 결정되고 와 $\rho$ 는 직선 모델 에 맞도록 결정된다[1].

$$
x \cos \theta+y \sin \theta=\rho
$$

본 알고리즘에서는 평균값을 구해 차선의 안쪽과 바 깥쪽 가장자리에 있는 가장 강한 선을 선택하였다.

\section{V-ROI 방식의 차선 인식}

직사각형 $\mathrm{ROI}$ 방식을 이용하여 차선을 인식할 경 우 잡음이나 잘못된 선들이 탐지되어 추가적인 처리 연산이 필요하고 차선을 잘못 인식하는 경우도 발생 한다. 이러한 문제를 해결하기 위해 ROI 결정 방식을 개선한 $\mathrm{V}-\mathrm{ROI}(\mathrm{V}$-shaped $\mathrm{ROI})$ 를 제안한다. 이를 위 해 차선 경계선에 대한 방정식 (1)을 다음과 같이 수 정한다. 


$$
-y=k\left(x-x_{0}\right)
$$

여기서 $\left(\mathrm{x}_{0}, \mathrm{y}_{\mathrm{o}}\right)$ 는 오른쪽과 왼쪽의 차선 경계선의 직 선식이 만나는 점의 좌표이고 $\mathrm{k}$ 는 식 (1)의 $\theta$ 로부터 얻어지는 기울기이다. $\mathrm{k}$ 값을 \pm 0.2 만큼 변화시켜 그림 2(b)와 같이 역방향 $\mathrm{V}$ 자 모양의 $\mathrm{ROI}$ 를 얻을 수 있다. \pm 0.2 라는 값은 정상적인 주행 상태에서 차선이 움직 이는 최대 범위를 경험적으로 얻은 값이다. 따라서 도로 상황에 따라서 변경하는 것도 가능하다. $\mathrm{V}-\mathrm{ROI}$ 방식을 적용하기 위해서는 먼저 직사각형 $\mathrm{ROI}$ 를 통 해 차선 경계선을 탐지하고 그 기울기 $\mathrm{k}$ 를 구하는 초 기화 과정이 필요하다. 그 이후에는 $\mathrm{V}-\mathrm{ROI}$ 영역에서 $\mathrm{k}$ 값을 갱신한다. $\mathrm{V}-\mathrm{ROI}$ 는 기존의 방식에 비해 처리 영역을 크게 줄일 수 있어 연산 효율과 성능 향상에 효과가 좋다[1,3].

일반적으로 고속도로에서 정상 주행을 하는 경우 차량은 대체로 차선 가운데를 주행하므로 ROI의 변 화가 크지 않다. 이러한 사실을 이용하여 이전 프레 임의 차선 경계선 위치로부터 위에서 언급한 방법에 따라 $\mathrm{V}-\mathrm{ROI}$ 영역을 구한다. $\mathrm{V}-\mathrm{ROI}$ 내의 이미지는 직사각형 $\mathrm{ROI}$ 차선인식에서와 같은 방식으로 이진화 하여 그림 2(c)와 같은 결과를 얻는다. $\mathrm{V}-\mathrm{ROI}$ 영역은 차선 경계선 부분의 일부 영역만 포함되므로 잡음이 나 가로 성분의 선, 또는 잘못된 선이 포함될 가능성 이 낮다. 따라서 차선 경계선의 형태를 왜곡할 수 있 는 오프닝 처리 대신에 메디안 필터를 이용하여 그림 2(d)와 같은 스무딩(smoothing) 결과를 얻는다. 이후 에는 직사각형 ROI 차선인식과 마찬가지로 Canny 가 장자리 탐지와 Hough 변환을 이용하여 그림 2(e)의 윤곽선을 구한다. 그림 2(f)에 최종 차선 인식 결과가 나타나 있다.

현재 구현된 소프트웨어에서는 인식된 차선 경계선 에 직선을 그리는 방식이므로 곡선 차로의 경우에는 인식된 차선에 두 개의 직선을 그리면 서로 만나는 점이 그림 $2(\mathrm{~g})$ 에 나타난 바와 같이 도로의 차선의 중앙에 위치하지 않는다. 그러나 실제 도로가 곡선이 어도 완만하게 변하므로 차량 가까운 곳에서는 차선 경계선이 인식되고 계속 차량이 진행함에 따라 이를 따라감을 확인할 수 있었다. 따라서 곡선 도로에서도 차선 이탈 경고시스템은 작동한다.

$\mathrm{V}-\mathrm{ROI}$ 방식에서는 이전 프레임에서 차선의 기울기 에 대한 정보를 얻어오므로 차선 내에서 차량이 좌우 로 조금 움직이는 경우에는 $\mathrm{V}-\mathrm{ROI}$ 영역 내에 차선 경계선이 남아 있어 차선 인식에 영향을 미치지 않고 매 프레임마다 차선 경계선의 기울기가 갱신되어 적 응적으로 $\mathrm{V}-\mathrm{ROI}$ 가 설정된다.

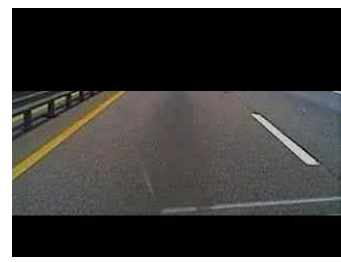

(a) Rectangular $\mathrm{ROI}$

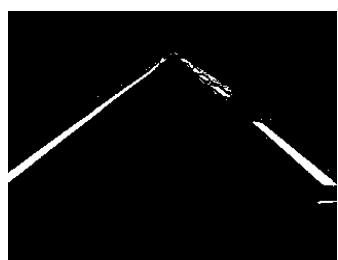

(c) Threshold result
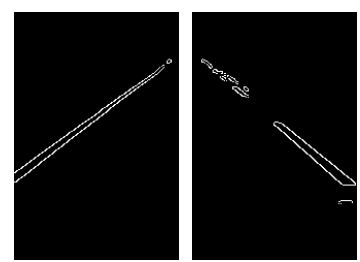

(e) Edge detection

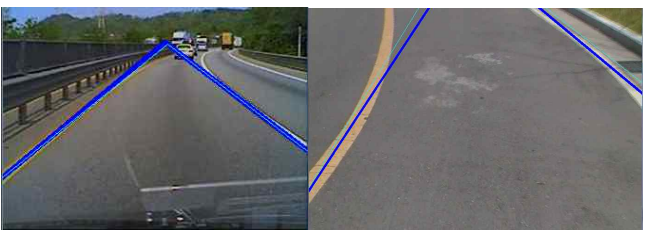

(g) Lane detection results in curved lane

Fig. 2. Lane detection procedure in $\mathrm{V}-\mathrm{ROI}$ 그림 2. $\mathrm{V}-\mathrm{ROI}$ 방식의 차선인식 과정

$\mathrm{V}-\mathrm{ROI}$ 방식의 차선인식을 이용하여 차선이탈 탐지 및 경고 신호를 발생시키기 위해 제안한 알고리즘에 서는 오류 프레임 카운터가 설정되어 다음 상황에서 는 $\mathrm{V}-\mathrm{ROI}$ 영역의 초기화가 이루어진다.

1. 주행속도에 따라 정해진 프레임 이상 $\mathrm{V}-\mathrm{ROI}$ 에서 하나의 직선이 발견되지 않는 경우

2. 탐지된 직선의 기울기가 허용된 범위를 벗어 나는 경우

1 의 경우에는 차량이 급격히 움직여 차선 이탈이 예 상되는 경우이며 2 번의 경우는 서서히 차선을 이탈하 고 있는 경우이다. 본 논문의 실험에서는 1 의 경우 3 프레임을 기준으로 잡았고 이는 0.1 초 동안 차선이 $\mathrm{V}$-ROI 영역에 나타나지 않는 경우이다. 이 프레임 수는 차량의 이동 속도에 따라 적응적으로 설정한다. 
둘 중 하나의 상황이 발생하면 $\mathrm{V}-\mathrm{ROI}$ 영역의 초기화 를 통해 차선 경계선을 재인식하고 차선 경계선의 기 울기를 측정하여 차선이탈 여부를 판단하고 경고 신 호를 발생시킨다. 그림 $3(\mathrm{~b})$ 는 위에서 언급한 상황이 발생하여 직사각형 ROI 방식으로 전환한 뒤, 차선 경 계선을 인식하고 경고 신호를 보내는 결과를 보여주 고 있다.

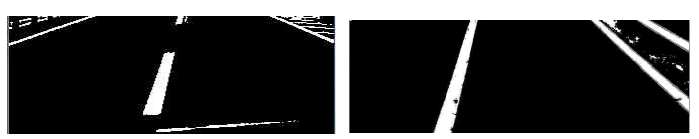

(a) Rectangular ROI
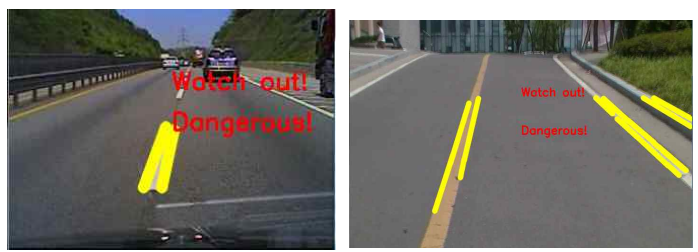

(b) Warning alarm generation

Fig. 3. ROI initialization and warning alarm generation when lane departure

그림 3. 차선이탈시 $\mathrm{ROI}$ 의 초기화와 경고신호 발생

제안한 알고리즘을 정리한 순서도가 그림 4에 나타 나 있다. 입력 영상이 들어오면 $\mathrm{V}-\mathrm{ROI}$ 를 적용할 수 있는 상황인지 아닌지를 판단하여 적용이 안 되는 상 황이면 즉 $\mathrm{V}-\mathrm{ROI}$ 초기화가 필요하면 직사각형 $\mathrm{ROI}$ 를 먼저 설정한 후 차선을 인식하고 차선의 기울기를 구한 뒤 다음 영상에 대한 처리를 진행한다. $\mathrm{V}-\mathrm{ROI}$ 처리가 가능한 상황에서는 $\mathrm{V}-\mathrm{ROI}$ 를 설정하고 선처리 를 진행한 뒤 좌우 두 개의 분할 영상에 대해 각각 차선 경계선 인식 과정을 진행한다. 여기에서 차선 경계선을 탐지하면 기울기를 구하고 그렇지 않으면 이전 기울기 값을 이용하여 다음 프레임에 대한 인식 작업을 수행한다. 그 후 차선 이탈 여부를 확인하여 결과를 보내고 다음 영상에 대한 처리를 진행한다. 좌우 영상에 대한 차선 인식 과정은 가장 연산량이 많고 독립적으로 진행이 가능하므로 다중 프로세서가 있는 경우 병렬 처리를 통해 연산 시간을 줄일 수 있 다. 따라서 듀얼 코어 이상의 스마트폰용 $\mathrm{AP}$ 에서도 실시간 처리가 가능할 것으로 예상된다.

차선 인식 알고리즘은 일반적으로 전방 카메라로부 터 입력된 영상에서 일정한 두께를 갖는 직선 또는 완만한 곡선을 인식하므로 그 대상의 형태가 복잡하 지 않다. 따라서 고해상도의 영상을 필요로 하지 않 는다. 이러한 사실을 이용하여 제안한 알고리즘에

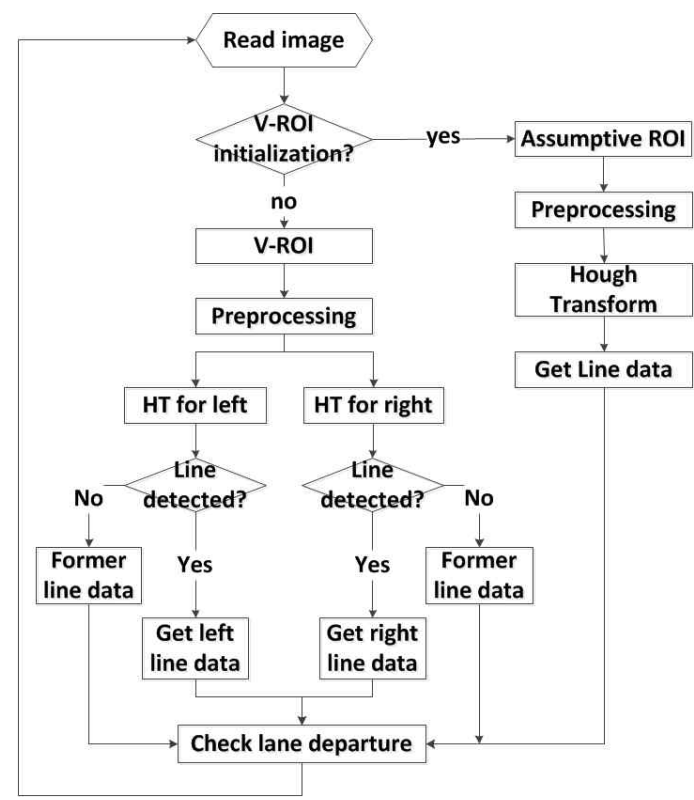

Fig. 4. Flow chart of the proposed algorithm

그림 4. 제안한 알고리즘의 순서도

서는 입력 영상의 해상도가 높을 경우에는 영상의 크 기를 축소하여 차선을 인식하도록 하였다. 영상 크기 축소는 최종 영상의 크기가 $\mathrm{QVGA}(320 \times 240)$ 와 비슷 해지는 범위에서 4 개 또는 9 개 픽셀의 평균값을 구하 여 대체하였다. 따라서 영상 크기에 연산 시간이 거 의 영향을 받지 않는다.

\section{IV. 구현 결과}

제안한 알고리즘에 따라 OpenCV 라이브러리를 이 용하여 차선인식 및 차선이탈 탐지 기능을 구현하였 다. 실행 환경은 $2.83 \mathrm{GHz}$ 의 $\mathrm{CPU}$ 를 갖는 데스크탑 $\mathrm{PC}$ 와 $2.4 \mathrm{GHz}$ 의 $\mathrm{CPU}$ 를 갖는 노트북과 윈도우즈 7 이 고 단일 코어만을 이용하여 실행하였다. 실험에 사용 한 영상은 $\mathrm{QVGA}$ 와 $\mathrm{SD}(720 \times 480)$ 해상도를 가지고 있다. $\mathrm{PC}$ 와 노트북은 $\mathrm{CPU}$ 동작주파수는 큰 차이가 없으나 전체적인 성능은 메모리 등의 주변장치 성능 차이로 응용 소프트웨어를 실행시켜 보면 두 배 정도 차이가 있다. 표 1 의 계산 시간 비교 결과를 보면 2.5 배 정도의 차이가 있음을 알 수 있다. 전체적인 계산 시간을 보명 Canny 가장자리 탐지와 Hough 변환이 대부분의 차지한다. Video2에서 괄호 안의 값은 영상 크기를 $360 \times 240$ 으로 축소하기 전의 계산 시간이고 괄 호 밖의 값은 축소 후의 계산이다. 입력 영상을 압축 할 경우 영상 크기에 따른 계산 시간의 차이는 거의 
없음을 볼 수 있다. 따라서 모두 프레임당 $30 \mathrm{~ms}$ 이내 에서 차선 인식이 가능하므로 실시간 동작이 가능하 다. 단일 코어만을 사용한 결과이므로 임베디드 시스 템에서 듀얼 코어 이상을 사용하고 코드를 최적화할 경우 역시 실시간 동작이 가능할 것으로 예상된다. 또한 다양한 동영상을 입력받아 실행한 결과 모두 정 상적으로 차선을 인식하였다.

Table 1. Calculation times according to the proposed algorithm

표 1. 제안한 알고리즘에 따른 계산 시간 [ms/frame]

\begin{tabular}{|c|c|c|c|c|}
\hline Platform & \multicolumn{2}{|c|}{ Desktop } & \multicolumn{2}{c|}{ Notebook } \\
\hline Video & video1* & video2** & video1** & video2** \\
\hline $\begin{array}{c}\text { (1) Pre- } \\
\text { processing }\end{array}$ & 1.1 & $\begin{array}{c}1.3 \\
(3.8)\end{array}$ & 2.7 & $\begin{array}{c}2.8 \\
(6.5)\end{array}$ \\
\hline $\begin{array}{c}\text { (2) Canny } \\
\text { edge }\end{array}$ & 1.2 & $\begin{array}{c}1.3 \\
(3.6)\end{array}$ & 4.1 & $\begin{array}{c}4.4 \\
(14.1)\end{array}$ \\
\hline $\begin{array}{c}\text { (3) Hough } \\
\text { Transform }\end{array}$ & 1.3 & $\begin{array}{c}1.7 \\
(3.9)\end{array}$ & 5.2 & $\begin{array}{c}4.9 \\
(15.5)\end{array}$ \\
\hline $\begin{array}{c}\text { (4) Calculation } \\
\text { (1)+(2)+(3) }\end{array}$ & 3.6 & $\begin{array}{c}4.3 \\
(11.3)\end{array}$ & 12 & $\begin{array}{c}12.1 \\
(36.1)\end{array}$ \\
\hline (5)Display & 2.8 & $\begin{array}{c}2.9 \\
(6.2)\end{array}$ & 4.6 & $\begin{array}{c}5.0 \\
(6.7)\end{array}$ \\
\hline Total (4)+(5) & 6.4 & $\begin{array}{c}7.2 \\
(17.5)\end{array}$ & 16.6 & $\begin{array}{c}17.1 \\
(42.8)\end{array}$ \\
\hline
\end{tabular}

* QVGA ** SD

표 2는 ROI 방식에 따른 연산 시간을 비교한 결과 이다. 표 1 의 영상 1 에 대해 데스크탑 컴퓨터에서의 연산 시간을 비교하였다. 첫 번째 열은 ROI를 사용하 지 않은 경우이고 $\mathrm{R}-\mathrm{ROI}$ 는 전체 면적의 $1 / 2$ 을 $\mathrm{ROI}$ 로 지정한 경우 세 번째 열은 $\mathrm{V}-\mathrm{ROI}$ 를 사용한 경우 이다. ROI 영역 전체에 대해 연산을 수행하는 선처리 과정에서 예상대로 $\mathrm{V}-\mathrm{ROI}$ 가 가장 큰 효과를 보이고 있다. Canny 가장자리 탐지와 Hough 변환은 주변에

Table 2. Comparison of calculation times for various ROI methods $[\mathrm{ms} / \mathrm{frame}]$

표 2. ROI 방법에 따른 연산시간 비교 [ms/frame]

\begin{tabular}{|c|c|c|c|c|}
\hline $\mathrm{ROI}$ & $\mathrm{No} \mathrm{ROI}$ & $\mathrm{R}-\mathrm{ROI}$ & $\mathrm{V}-\mathrm{ROI}$ & $\mathrm{V}-\mathrm{ROI} / \mathrm{R}-\mathrm{ROI}$ \\
\hline $\begin{array}{c}\text { (1) Pre- } \\
\text { processing }\end{array}$ & 2.0 & 1.5 & 1.1 & 0.73 \\
\hline $\begin{array}{c}\text { (2) Canny } \\
\text { edge }\end{array}$ & 2.3 & 1.4 & 1.2 & 0.86 \\
\hline $\begin{array}{c}\text { (3) Hough } \\
\text { Transform }\end{array}$ & 2.9 & 1.9 & 1.3 & 0.68 \\
\hline $\begin{array}{c}\text { (4) Calculation } \\
\text { (1)+(2)+(3) }\end{array}$ & 7.2 & 4.8 & 3.6 & 0.75 \\
\hline
\end{tabular}

차선 경계선 이외의 선이 얼마나 탐지되었는지에 따 라 결과가 달라지는데 임계값 결정과정에서 많은 불 필요한 선들이 제거되므로 $\mathrm{V}-\mathrm{ROI}$ 의 사용으로 얻는 이득은 $40 \%$ 정도이다.

표 3 은 본 논문의 실험 결과와 기존 결과를 비교한 것이다. 비교 결과를 보면 플랫폼에 따른 성능 차이 를 감안하여도 제안한 알고리즘에 따른 결과가 가장 우수함을 알 수 있다.

Table 3. Comparison results of calculation time with other works

표 3. 기존의 결과와의 계산 시간 비교

\begin{tabular}{|c|c|c|c|}
\hline & Platform & Image size & Detection time [ms] \\
\hline Qing Lin[1] & $\begin{array}{c}\text { Intel Core2 } \\
1.86 \mathrm{GHZ}\end{array}$ & $720 \times 480$ & $30-50$ \\
\hline Gaikwad[6] & $\begin{array}{c}\text { Intel i3 } \\
2.53 \mathrm{GHz}\end{array}$ & $\mathrm{N} / \mathrm{A}$ & 54 \\
\hline Proposed & $\begin{array}{c}\text { Intel Core2 } \\
2.83 \mathrm{GHZ}\end{array}$ & $720 \times 480$ & $7-12$ \\
\hline
\end{tabular}

\section{V. 결론}

본 논문에서는 $\mathrm{ROI}$ 영역을 줄이고 입력 영상을 압 축하여 연산량을 줄이는 차선 인식 알고리즘을 제안 하였다. 제안한 알고리즘에서는 입력된 영상에 대해 선처리(preprocessing) 과정을 통해 영상을 축소하여 이미지 크기를 줄이고 차선 경계선 후보를 선택하여 그 주변만을 ROI로 지정하는 $\mathrm{V}-\mathrm{ROI}$ 방법을 통해 기 존에 비해 연산량을 줄이면서 입력 영상의 해상도에 관계없이 거의 일정한 연산량을 유지하여 고해상도 영상에서도 성능이 저하되지 않는다. 제안한 알고리 즘을 적용하고 $\mathrm{OpenCV}$ 라이브러리를 이용하여 윈도 우즈 환경에서 차선 인식 소프트웨어를 구현하였으며 $\mathrm{SD}$ 해상도 영상에 대해 프레임당 $\mathrm{PC}$ 에서 $7 \mathrm{~ms}$, 노트 북에서 $17 \mathrm{~ms}$ 로 실시간 동작함을 확인하였다. 또한 추 가적인 압축과 코드 최적화를 통해 계산 시간을 더욱 줄일 수 있어 임베디드 시스템에서도 실시간 동작이 가능할 것으로 예상된다.

\section{References}

[1] Qing Lin, Youngjoon Han and Hernsoo Hahn, "Real-time Lane Detection Based on Extended Edge-linking Algorithm", Second International Conference on Computer Research and Development, pp. 725 -730, May 7-10, 2010, Kuala Rumpur, Malaysia

[2] Joel C. McCall and Mohan M. Trivedi, 
"Video-based Lane Estimation and Tracking for Driver Assistance: Survey, System, and Evaluation", IEEE Transactions on Intelligent Transportation Systems, Vol. 7, pp. 20-37, 2006

[3] Xu Zhe, Li Zhifeng, "A robust lane detection method in the different scenarios", Proceedings of 2012 IEEE International Conference on Mechatronics and Automation, pp. 1358-1363, Aug. 5-8, 2012, Chengdu, China

[4] Shengyan Zhou, Yanhua Jiang, Junqiang $\mathrm{Xi}, " A$ Novel Lane Detection based on Geometrical Model and Gabor Filter", 2010 IEEE Intelligent Vehicles Symposium, pp. 59-64, June 21-24, 2010, San Diego, USA

[5] Claudio Rosito Jung, Christian Roberto Kelber, "Lane following and lane departure using a linear-parabolic model', Image and Vision Computing, Vol. 5, pp. 1192-1202, 2005

[6] Vijay Gaikwad, Shashikant Lokhande, "An improved lane departure method for Advanced Driver Assistance System", International Conference on Computing, Communication and Applications (ICCCA), pp. 1-5, Feb. 22-24, 2012, Tamilnadu, India

[7] P.M. Daigavan and P. R.Bajaj, "Road Lane Detection with Improved Canny Edges Using Ant Colony Optimization", Third International Conference on Emerging Trends in Engineering and Technology, pp. 76-80, Nov. 19-21, 2010, Goa, India [8] Lee Kim Kuan, Ismail N.H, "Lane Guidance Warning System", International Conference on Computer and Communication Engineering (ICCCE 2012), pp. 864 - 868, July 3-5, 2012, Kuala Lumpur, Malaysia

[9] Jung Gap Kuk, Jae Hyun An, "Fast lane detection \& tracking based on Hough transform with reduced memory requirement", 13th International IEEE Annual Conference on Intelligent Transportation Systems, pp. 1344-1349, Sep. 19-22, 2010, Madeira Island, Portugal

[10] Nobuyuki Otsu, "A threshold selection method from gray-level histograms". IEEE Trans. Sys., Man., Cyber. Vol. 9(1), pp. 62-66. 1979

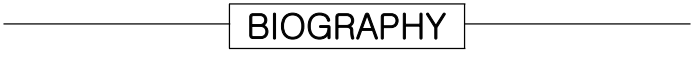

Ding Dajun (Student member)

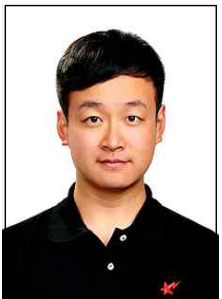

2010 : BS degree in Electronic and Information Engineering, Shandong University of Science and Technology.

2011 present : Graduate student in MS degree in Dept. of Electronic Engineering,

Soongsil University

$<$ Research Area> Image Pattern Recognition

Lee Chanho (Member)

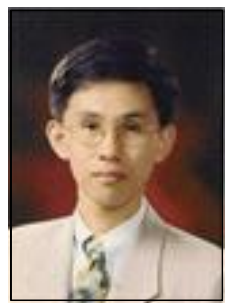
1987 : BS degree in Electronic Engineering, Seoul National University. 1989 : MS degree in Electronic Engineering, Seoul National University. 1994 : Ph.D degree in Electrical Engineering, University of California Los Angeles

1994 1995 : Senior Research Engineer, Samsung Electronics.

1995 present : Professor, School of Electronic Engineering Soongsil University $\langle$ Research Area> SoC on-chip-network, Memory controller, Image Pattern recognition, SoC design methodology, Implementation of video codec 